
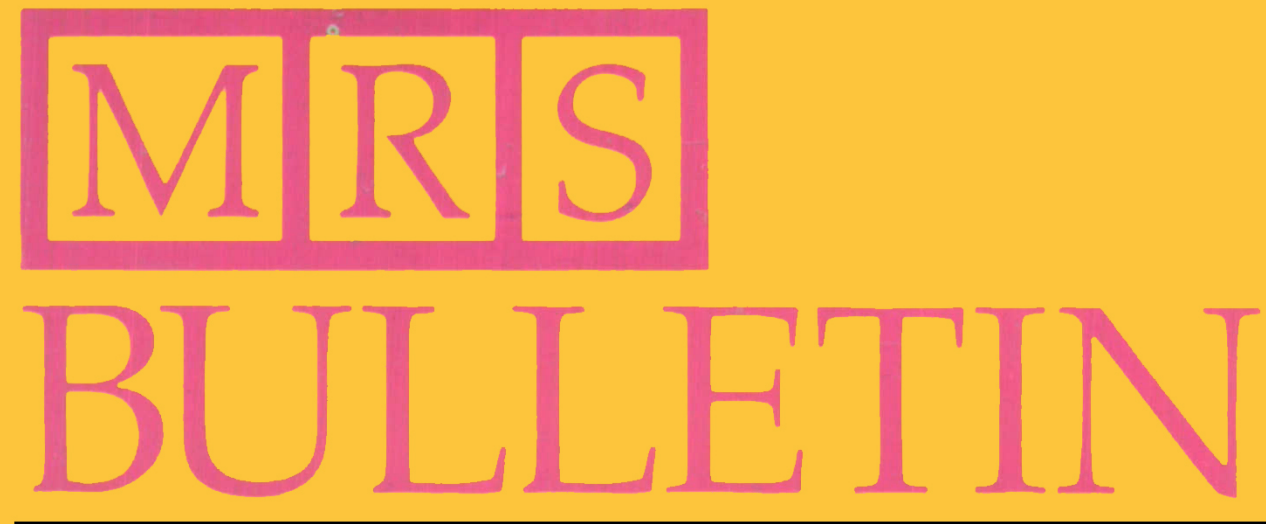

March 1990

Serving the International Materials Research Community

\title{
Magnetic Recording Materials
}

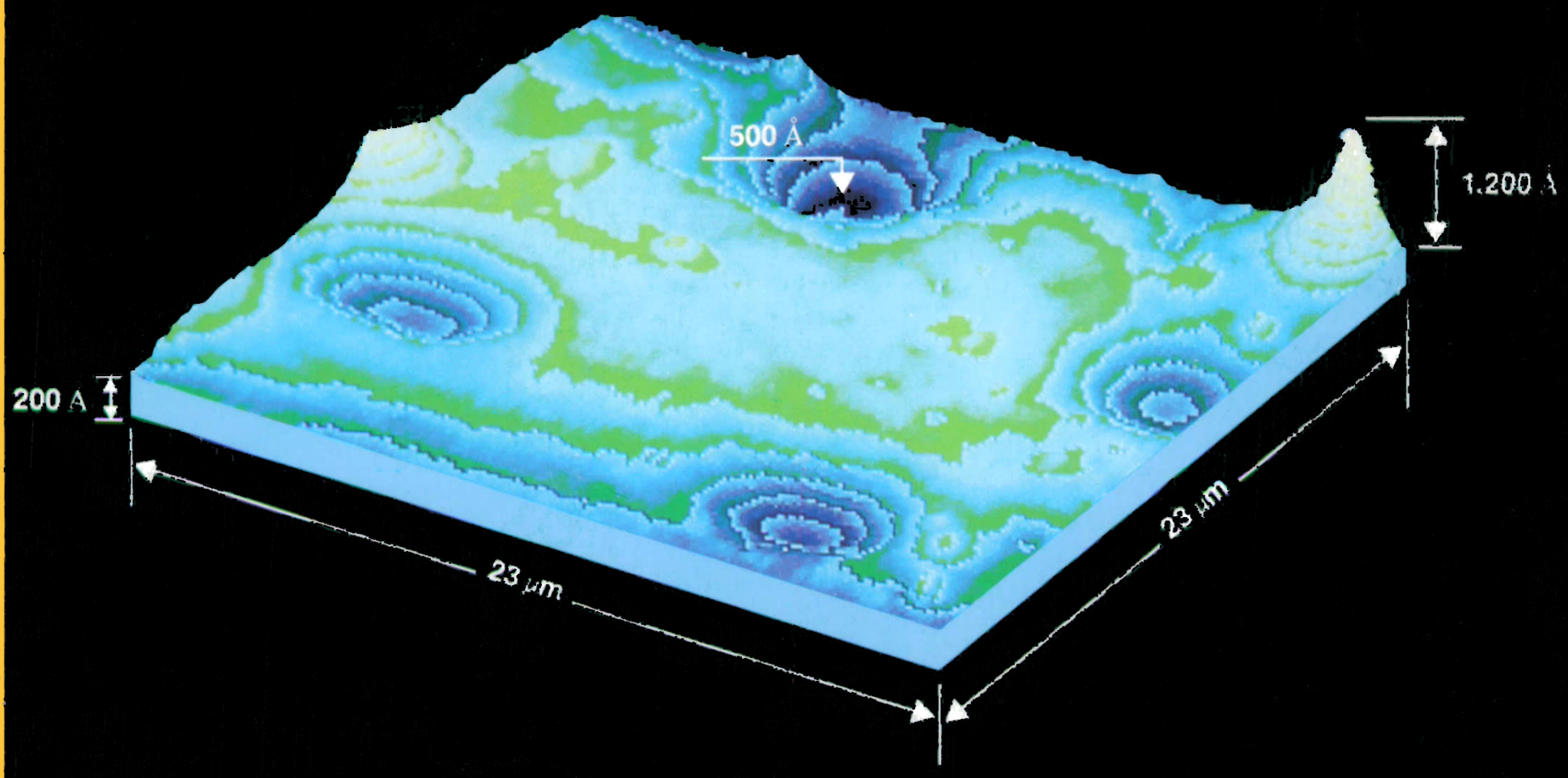




\section{$A N E W$ CLUSTER ISBORN}
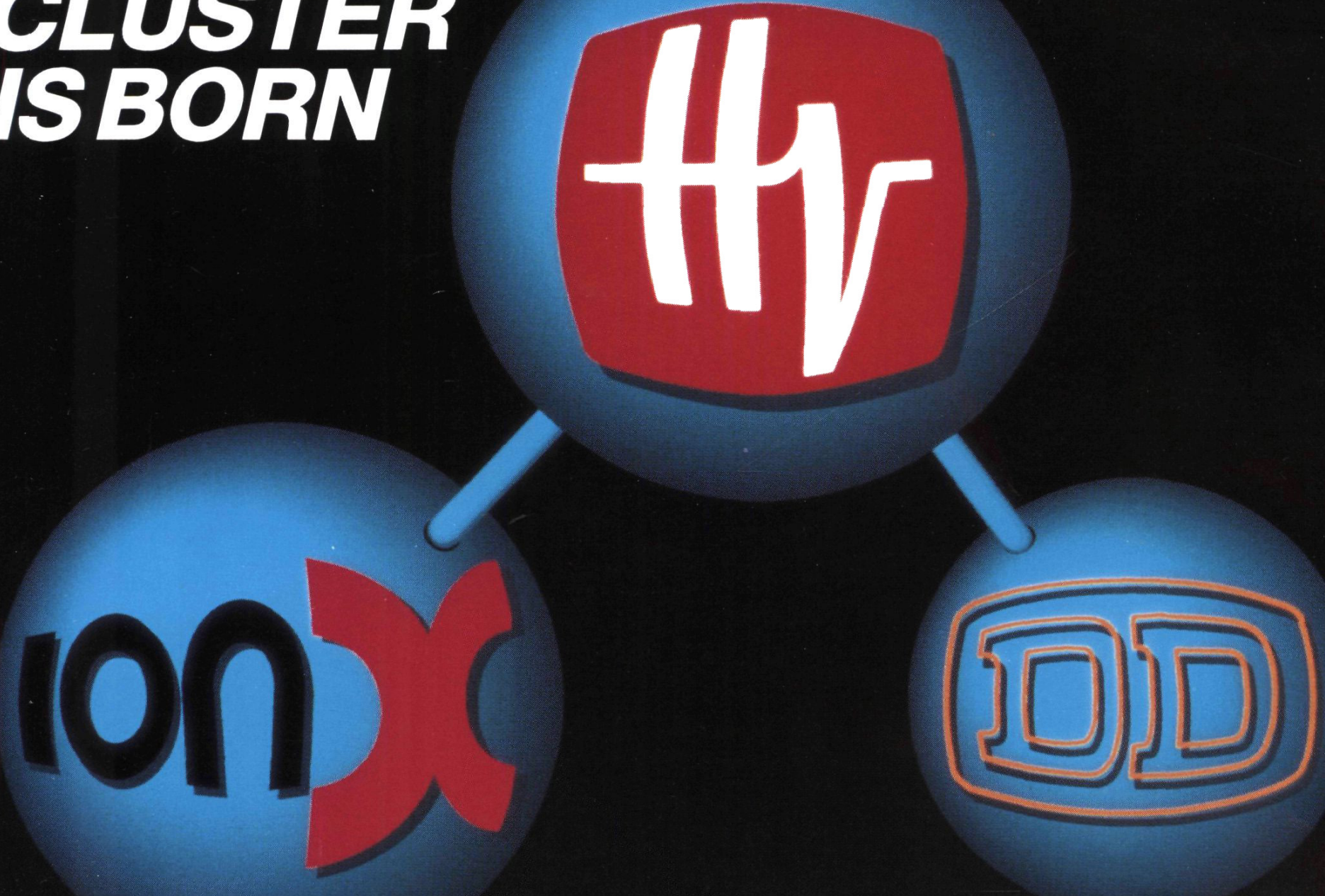

\section{General lonex acquired by High Voltage Engineering Europa B.V.}

In December 1987 High Voltage Engineering Europa B.V.

(HVEE) acquired Dowlish Developments Ltd (DD), an accelerator tube manufacturer located in the United Kingdom.

On April 10, 1989, HVEE purchased the General lonex Analytical Product Group from Genus Inc. based in the United

States.

Through this acquisition HVEE positions itself as the largest and most diverse manufacturer of particle accelerators for the scientific and industrial research communities.

The acquired General lonex (GI) product lines, which include

the Tandetron accelerator systems and Model 4175 RBS Analyser, will be manufactured in HVEE's new, well-equipped facility in Amersfoort, The Netherlands.

World wide marketing of all products from HVEE, DD and GI will originate from HVEE Amersfoort with sales and service offices in the USA, Europe and Japan.
After addition of the newly acquired products HVEE's product lines include:

- Ion Accelerator Systems

- Air insulated accelerators up to $500 \mathrm{kV}$

- Single ended Van de Graaff accelerators up to 4 MV

- Tandem Tandetron accelerators up to 3 MV/TV

- Research ion implanters

- Beam energies $10 \mathrm{keV}-9 \mathrm{MeV}$ and higher

- Systems for ion beam analysis

- Systems for RBS, PIXE, PIGE, NRA, ERD, MACS and MEIS

- Components

- HV power supplies, electron and ion accelerator tubes, ion sources beamline components, beam monitoring equipment, UHV sample manipulators, etc.

For further information on this transaction and product literature please contact HVEE in Amersfoort/NL. 


\section{MIRIS

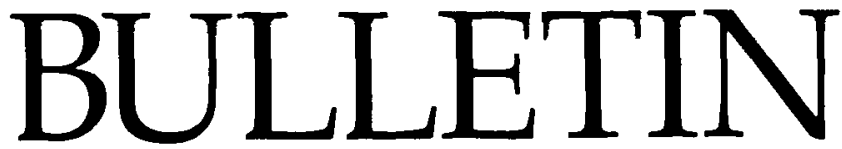

March 1990

A Publication of the Materials Research Society

Volume XV, Number 3 ISSN: 0883-7694 CODEN: MRSBEA

\section{MAGNETIC RECORDING MATERIALS}

23 Magnetic Recording Materials: Present and Future

A. Berkowitz, Guest Editor

31 Magnetic Storage: Principles and Trends J.U. Lemke

36 Materials for Future High Performance Magnetic Recording Heads T. Jagielinski

45 Overcoats and Lubrication for Thin Film Disks

A.M. Homola, C.M. Mate, and G.B. Street

53 Particulate Recording Media

M.P. Sharrock

63 Thin Film Recording Media J.H. Judy

\section{INTERNATIONAL}

73 International Materials Research Committee Holds Inaugural Meeting

\section{MRS NEWS}

77 Plans Launched for Establishing MRS Washington, DC Office

81 Spring Meeting Plenary Questions Earthquake Predicition Theories

821990 Von Hippel Award Nominations Sought

82 MRS Offers Major New Awards

84 Fall ' 89 Meeting Features Broad Mix of Topics

\section{DEPARTMENTS}

4 Letter from the President

7 Material Matters

8 Research/Researchers

18 Research Resources

26 Journal of Materials Research

88 Historical Note

92 Upcoming Conferences

94 Book Reviews

95 Calendar

100 Classified

104 Advertisers in this Issue

104 Posterminaries

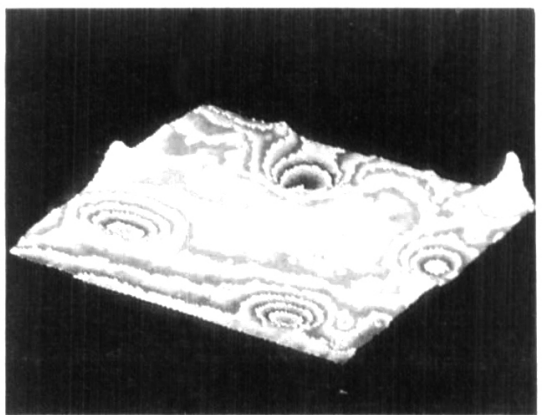

ON THE COVER: The cover shows a threedimensional micrograph obtained by atomic force microscopy (AFM) of the surface of a liquid, perfluoropolyether polymer spread on a substrate patterned with micron-sized holes. The same type of polymer is commonly used to lubricate magnetic storage devices. The color contours in the micrograph highlight the menisci of the liquid in the hole openings of the substrate. From the work of C.M. Mate. For more information, see "Overcoats and Lubrication for Thin Film Disks" by A.M. Homola, C.M. Mate, and G.B. Street on p. 45. 
Materials Research Soclety • 9800 McKnight Road • Pittsburgh, PA 15237

MRS BULLETIN

\section{Editor}

G. A. Oare

(412) $367-3036$

Assistant Editor

F. M. Wieloch

(412) $367-3036$

Copy Editor

S. W. Morelli

Design/Production

C. Love, W. Appman

(412) $367-3003$

Editorial Assistant

J. Dininny

(412) $367-3036$

Advertising and Circulation

M. E. Kaufold

(412) 367.3036

\section{MRS EXECUTIVE COMMITTEE}

\section{President \\ R. R. Chianelli \\ Exxon Research \\ and Engineering}

First Vice President and

President-Elect

J. B. Roberto

Laboratory

Second Vice President

S. Cargill

IBM T.J. Watson

Research Center
Oak Ridge National
Associate Editor-Europe

I. W. Boyd

University College London

Dept. of Electronic and

Electrical Engineering

Torrington Place

London WCI E7 JE

United Kingdom

01-387-7050

ext. 3956 or 7304

\section{Contributor}

K. J. Anderson

Guest Editor

A. Berkowitz

Secretary

C.M. Jantzen

Westinghouse Savannah

River Co.

Treasurer

S. M. Kelso

Therma-Wave, Inc.

Immediate Past President

R. P. H. Chang

Northwostem University

\section{Executive Director \\ Materials Research Society \\ John B. Ballance}

\section{EUROPEAN MRS}

\author{
P. Siffert \\ Centre de Recherches Nucléaires \\ Laboratoire PHASE \\ 67037 Strasbourg, Cedex, France \\ Telephone: (88) 286543 \\ Fax: (88) 280990
}

\author{
Chairman-Editorial Boards \\ E. N. Kaufmann \\ Argonne National Laboratory \\ Argonne, llinois
}

Intemational Advisory Boand

\section{Balkanski \\ R. Roy}

University of Pierre and Marie Curie Pennsylvania State University

Paris, France University Park, Pennsylvania

S. Hsu Chung Shan Institute of Science
and Technology

G. D. W. Smith

University of Oxford

Taiwan, China

R. Krishnan

Defense Research and

Development Organization

New Delhi, India

H. D. Li

Tsinghua University

Beijing, China

Oxford, United Kingdom

T. Sugano

University of Tokyo

Tokyo, Japan

J. S. Williams

Royal Melbourne Institute of

Technology

Melbourne, Australia

Technical Editorial Board

J. C. C. Fan

Kopin Corporation

Taunton, Massachusetts

\section{R. L. Schwoebel}

F. Y. Fradin

Argonne National Laboratory

Argonne, Illinois

Sandia National Laboratories

Albuquerque, New Mexico

\section{G. L. Liedl}

Purdue University

West Lafayette, Indiana

\section{R. C. Sundahl}

Intel Corporation

Chandler, Arizona

S. Namba

Osaka University

Osaka, Japan

MRS BULLETIN

Publications Subcommittee

M. H. Bennett-Lilley

Texas Instruments

Dallas, Texas

K. C. Taylor

General Motors

Warren, Michigan

R. R. Chianelli

General Electric

Largo, Florida

Exxon Research and Engineering

Annandale, New Jersey

J. M. Phillips

R. J. Eagan

Sandia National Laboratories

Albuquerque, New Mexico
AT\&T Bell Laboratories

Murray Hill, New Jersey

C. W. White

Oak Ridge National Laboratory

Oak Ridge, Tennessee

\section{ABOUT THE MATERIALS RESEARCH SOCIETY}

The Materials Research Society (MRS) is a nonprofit scientific association founded in 1973 to promote interdisciplinary goal-oriented basic research on materials of technological importance. Membership in the Society includes more than 9,500 scientists from industrial, government, and university research laboratories in the United States and more than 25 countries.

The Society's interdisciplinary approach to the exchange of technical information is qualitatively different from that provided by single-discipline professional societies because it promotes technical exchange across the various fields of science affecting materials development. MRS sponsors two major international annual meetings encompassing approximately 40 topical symposia, as well as numerous singletopic scientific meetings each year. It recognizes professional and technical excellence, conducts short courses, and fosters technical exchange in various local geographic regions through Section activities and University Chapters.

MRS is an Affiliated Society of the American Institute of Physics and participates in the international arena of materials research through associations with professional organizations such as European MRS.
MRS publishes symposium proceedings, the MRS BULLETIN, Joumal of Materials Research, and other current scientific developments.

MRS BULLETIN (ISSN: 0883-7694) is published 12 times a year by the Materials Research Society, 9800 McKnight Road, Pittsburgh, PA 15237. Membership in MRS includes $\$ 25.00$ ( $\$ 15.00$ for students) from membership dues to be applied to a subscription to the MRS BULLETIN. Application to mail at second class rates is pending at Pittsburgh, PA and at additional mailing offices. POSTMASTER: Send address changes to MRS BULLETIN in care of the Materials Research Society, 9800 McKnight Road, Pittsburgh, PA 15237; telephone (412) 367-3003; fax (412) 367-4373. Back volumes of this publication are available in $16 \mathrm{~mm}$ microfilm, $35 \mathrm{~mm}$ microfilm, or $105 \mathrm{~mm}$ microfiche through University Microfilms Inc., 300 North Zeeb Road, Ann Arbor, Michigan 48106. 


\section{UHV ECR Source}

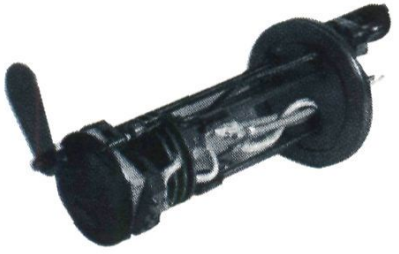

DOO Degree C Heater

The MICRO1000 range of heaters operate up to 1000 degrees C. even in an oxygen environment. Available in a number of configurations to fit any vacuum system. Comes with a range of optional accessories including shutter, cooling shroud and DC and RF biasing. For more information call Microscience, 41 Accord Park Dr. Norwell, MA02061. Tel. (617) 871-0308.

\section{Small Batch Sputter Production Systems}

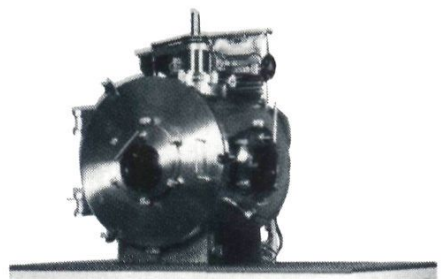

The Microscience MicroProd sputter system is suitable for prototype and batch production work with small substrates. Features a 24 inch dia. barrel chamber, loading door, carousel sample holder, and a variety of ports and feed throughs for magnetron sputter guns and ion sources. The MicroProd is a CAD design that can be easily adapted for a wide range of uses. Contact Microscience, 41 Accord Park Dr., Norwell, MA 02061. Tel. (617) 871-0308.

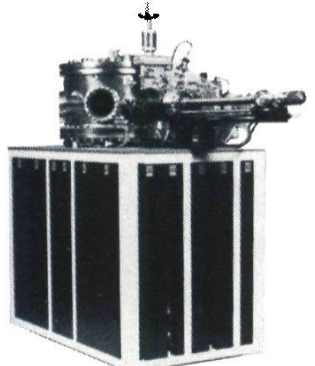

Researcher 101

Microscience introduces the researcher 101. An integrated UHV thin film system for advanced R\&D applications. Originally designed for research on HTC films, the 101 incorporates many specialized features including transportable 1000 degree heater substrate carrier, stepper motor controlled, substrate positioning system and optional surface science module. The 101 is offered in HV and UHV configurations and can be fitted with a wide range of tools including planar magnetrons, ion sources and an ECR plasma stream source. From Microscience, 41 Accord Park Dr, Norwell, MA 02061.Tel (617) 871-0308.
The Microscience 904 ECR source is designed for retrofitting to UHV chambers. The source comes complete with microwave circuitry, magnets and power supplies. Details from Microscience,

41 Accord Park Dr., Norwell,

MA 02061. Tel. (617) 871-0308.

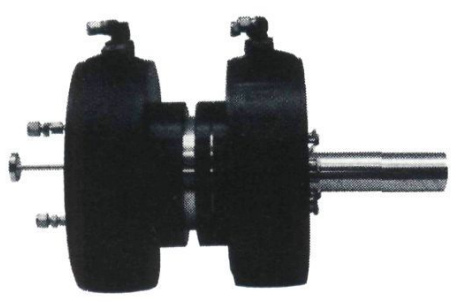
ECR plasma stream source fitted with extraction grids for energies in the range 50-5000 eV. The 908G produces beam densities up to $100 \mathrm{~mA} / \mathrm{cms}$. Applications include ion beam enhanced deposition, ion etching and RIBE. Contact Microscience, 41 Accord Park Dr. Norwell, MA 02061. Tel. (617) 871-0308.
MBE Sputter System

The Microscience 401 sputtering system is designed for interfacing to MBE systems. Features include a transfer system, load lock, rotating heated biasable sample holder magnetron cluster and an LN cryoshroud. This is a CAD based design that can be adapted for most MBE systems. Contact Microscience, 41 Accord Park Dr., Norwell, MA 02061. Tel. (617) 871-0308.

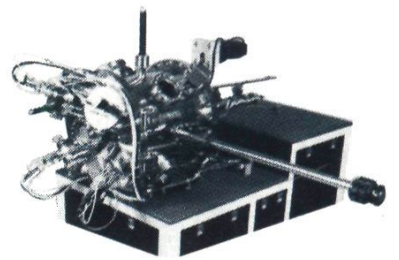

Please visit Booth No. 613 at the MRS Show in San Francisco, April 17-19, 1990.
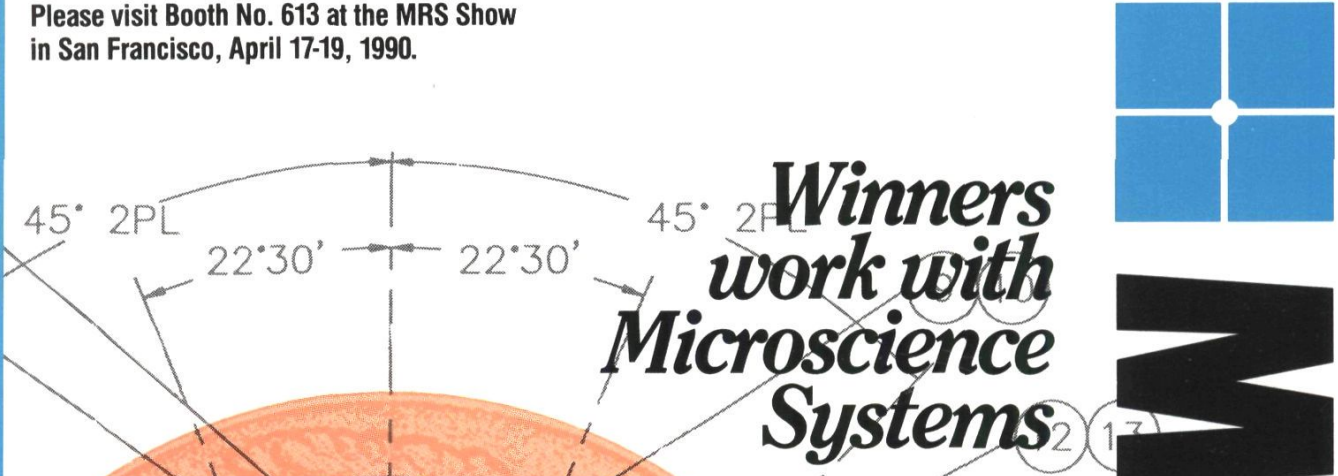

We can't guarantee you't win a Nobel prize using our thin film systems

but uye can promise you innovative, cost effective designs for state of the art systems. Whether your interest is a small research system, a production tool or? thin film laboratory, comprehensive thin fil
our CAD department can tailor a system to suit your needs. You can choose from a wide range of industry standard components and take advantage of our innovative technical advances in plasma sources, heafers, subsrate handling, computer control and information managers.

So, if you want to win in thin films, give Microscience a call.

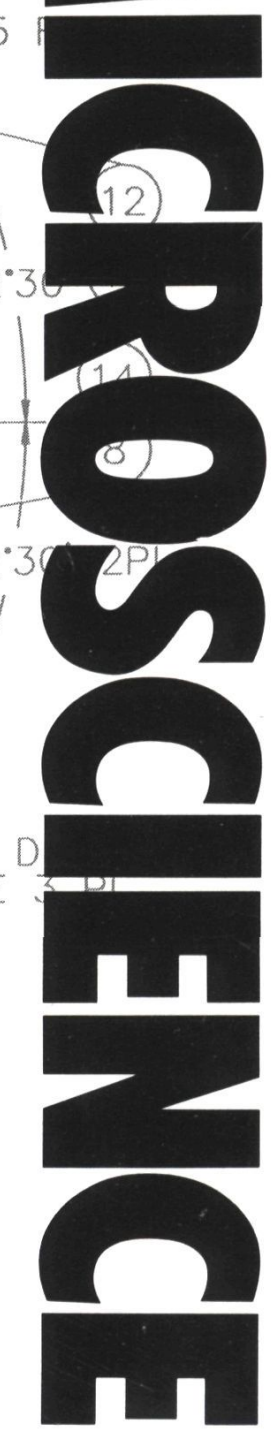

